\title{
Professor, dividir não diminui? Relativizando possíveis verdades matemáticas mediante o uso da calculadora.
}

\author{
Wagner da Silveira Marques \\ Professor, UCAM e FAETEC/RJ \\ wagsm@ig.com.br
}

\begin{abstract}
Resumo
Relativizar verdades matemáticas pode ser um bom caminho para permitir a construção do conhecimento dos alunos. Trazemos o recorte de uma pesquisa na qual foram implementadas atividades instigadoras em um grupo de alunos do primeiro ano do Ensino Médio Profissionalizante, trabalhando em duplas, com o objetivo de verificar como eles se comportam diante de uma divisão representada por uma fração cujo denominador é um número decimal compreendido entre zero e um, promovendo uma análise sob a luz de Vygotsky e Bakhtin. Nossos instrumentos de coleta de dados foram o diário de campo do investigador, as respostas das atividades, as reflexões individuais dos alunos e gravações em áudio A primeira análise destaca que uma dupla de discentes, para a qual a atividade se mostrou instigadora desde o início, exibiu indícios de apropriação de nova realidade conceitual, desconstruindo a ideia de que dividir sempre diminui, à medida que pistas eram fornecidas. A segunda análise revela que a desestabilização provocada pelo professor sobre uma estudante faz com que a mesma aparente ter transformado sua verdade em dúvida, momento em que a atividade passa a se mostrar instigadora, mas que não parece demonstrar que a aluna tenha passado a um novo nível de conhecimento. Embora a calculadora ainda seja um recurso antigo, pode, mesmo em tempos atuais, ser inovadora em sala de aula.
\end{abstract}

Palavras-chave: Divisão. Calculadora. Atividades Instigadoras.

\section{Teacher, to divide not decreases? Relativizing mathematical truths through the use of the calculator.}

\begin{abstract}
Relativize mathematical truths can be a good way to allow the construction of student knowledge. We bring part of a research in which instigators activities were implemented in a group of students from the first year of professional high school, working in pairs, with the objective to see how they behave before a division represented by a fraction whose denominator is a decimal number between zero and one, promoting an analysis in the light of Vygotsky and Bakhtin. Our data collect instruments were the researcher's field diary, the responses of activities, individual reflections of students and audio recordings. The first analysis points out that a couple of students, for which the activity was shown instigator from the beginning, which showed evidence of new conceptual reality of ownership, as clues were provided, observing a transition the zone of proximal development. The
\end{abstract}


second analysis shows that the destabilization caused by the teacher over a student makes the same appears to have turned his truth in doubt, when the activity goes to show instigator, but that seems to show that the student has passed a new knowledge level. Although the calculator is still an old resource, it can even in modern times, be innovative in the classroom.

Keywords: Division. Calculator. Instigators Activities.

\section{A pergunta}

Professor, pode usar a calculadora? Ao introduzir essa pergunta (os alunos invariavelmente perguntam pode e não posso), de imediato fui remetido ao verso de Mario Lago em parceria com Ataulfo Alves (1944) - diga-se de passagem, um aparceiramento e tanto! - que dizia "atire a primeira pedra aquele que não sofreu por amor." Num primeiro momento, o leitor pode imaginar que há algo desconexo com essa associação, mas quantas vezes não fizemos esta pergunta, sobre usar a calculadora, aos nossos professores, enquanto estudantes, e quantas outras não ouvimos de nossos alunos tal indagação? Alguém se arriscaria a atirar a primeira pedra?

E sofrer por amor? Às vezes, sofremos por algo que está tão próximo e tão distante ao mesmo tempo, como uma pessoa do nosso convívio que amamos e sequer consegue perceber, valorizar e retribuir nosso sentimento. Da mesma forma, de que adianta termos a tecnologia nas mãos se não somos estimulados a utilizá-la e, na maior parte das ocasiões, impedidos de fazê-lo ou de desenvolver outras formas de pensar e calcular?

Embora a inquirição sobre o uso da calculadora no ensino seja um tanto antiga, não é raro presenciarmo-la ainda em sala de aula, durante aulas que envolvam quaisquer tipos de cálculos, principalmente aqueles extensos e com números ditos mal comportados ${ }^{1}$. Mesmo sendo um recurso considerado antigo, graças à data de sua invenção, parece-nos ainda muito ausente no ato de educar, de ensinar, pois a resposta mais comum dada pelos docentes à pergunta anterior é um não.

Não permitir que o discente utilize a calculadora em sala de aula por temer que o mesmo se torne preguiçoso, não se proponha mais a se esforçar na realização das contas, tenha seu raciocínio inibido e se torne dependente da ferramenta são as justificativas mais presentes entre os professores que se mostram contra o uso desse recurso pelos estudantes (BORBA; SELVA, 2009). No entanto, têm-se revelado várias pesquisas que apoiam o uso da calculadora, nas quais essa prática possibilitou a exploração de conceitos matemáticos e a construção do conhecimento através de atividades com a utilização desse recurso, conforme sinalizado a seguir (Quadro 1).

\footnotetext{
${ }^{1}$ Antônio José Lopes, mais conhecido como Bigode, tendo em vista o embaraço que os alunos apresentam nas contas com números decimais, aqueles que apresentam a vírgula entre os dígitos, nomeou-os números mal comportados. Maiores esclarecimentos podem ser obtidos em Bigode (1997, 2005).
} 
Quadro 1 - Síntese de pesquisas com êxito utilizando a calculadora

\begin{tabular}{|c|c|c|c|c|}
\hline Pesquisador & Ano & Público & Âmbito & Temática \\
\hline Selva e Borba & 2010 & Alunos & $\begin{array}{c}\text { Ensino } \\
\text { Fundamental }\end{array}$ & Diversos $^{2}$ \\
\hline Seixas e Silva & 2010 & Alunos & Ensino Médio & $\begin{array}{l}\text { Problemas } \\
\text { matemáticos }\end{array}$ \\
\hline $\begin{array}{l}\text { Scheffer e } \\
\text { Dallazen }\end{array}$ & 2012 & $\begin{array}{c}\text { Professores e alunos } \\
\text { de IC }\end{array}$ & Ensino Médio & Funções \\
\hline Silva e Castro & 2012 & Alunos & Ensino Médio & $\begin{array}{c}\text { Números racionais } \\
\text { e irracionais }\end{array}$ \\
\hline Marques & 2012 & $\begin{array}{l}\text { Professores e } \\
\text { graduandos em } \\
\text { Matemática }\end{array}$ & Ensino Superior & Diversos \\
\hline Marques & 2013 & $\begin{array}{l}\text { Graduandos em } \\
\text { Matemática }\end{array}$ & Ensino Superior & Diversos \\
\hline
\end{tabular}

Fonte: Elaborado pelo autor.

Recentemente, realizamos uma investigação na qual analisamos a implementação de atividades instigadoras associadas à calculadora comum, de bolso (MARQUES; BAIRRAL, 2014). Definimos atividades instigadoras como aquelas que averiguam o uso ou a aplicação de conhecimentos prévios, que podem estimular e despertar o interesse para aprender, que possibilitam a construção do conhecimento a partir de descobertas e que despertam reflexão sobre a relativização de verdades matemáticas, atividades essas que também podem ser aplicadas em quaisquer áreas do conhecimento, com suas devidas adaptações. Naquela oportunidade, apresentamos um recorte ${ }^{3}$ que promoveu a análise de uma atividade relacionada às teclas de memória e de uma sequência de tarefas realizadas por um aluno específico.

No presente artigo, pretendemos verificar como estudantes do ensino médio se comportaram diante de uma divisão representada por uma fração cujo denominador é um número decimal compreendido entre zero e um, por exemplo, $1 \div 0,5$ ou, dito de outra forma, um inteiro dividido pela sua metade. A ideia inicial que parece prevalecer é que sempre encontramos um número menor que o inicial quando efetuamos uma divisão, mesmo que a calculadora mostre o

\footnotetext{
${ }^{2}$ Temáticas diversas envolveram vários tipos de operações matemáticas, englobando assuntos diversificados, bem como a utilização de jogos matemáticos.

${ }^{3}$ Maiores elucidações sobre o recorte mencionado e sua referida análise podem ser encontrados em Marques e Bairral (2014).
} 
oposto $^{4}$. A fim de estear nossas observações acerca do desempenho dos estudantes envolvidos, traremos ao diálogo alguns estudiosos.

\section{Bases para a divisão}

Ao tratar da questão do aprendizado, Thorndike ${ }^{5}$ (apud VYGOTSKY, 1991) sublinha que aprender envolve bem mais que adquirir uma competência para a reflexão, pois engloba aptidões especializadas necessárias para argumentar sobre múltiplas ideias. Salienta, ainda, que o aprendizado desenvolve capacidades de evidenciar várias coisas, não desorganizando nossa competência global de focar a atenção exclusivamente num determinado fato.

Corroborando esse pressuposto, Vygotsky (1991) sinaliza que existe um grupo de teorias que apontam como aspecto essencial a ideia de que o aprendizado leva a desenvolvimentos cada vez maiores, destacando a importância de se observar que as crianças já apresentam algum tipo de aprendizado antes mesmo de elas frequentarem a escola. $\mathrm{O}$ que o estudante já carrega consigo em sua bagagem acaba sendo uma história prévia para uma nova situação de aprendizado que tenha pela frente durante sua educação. Assim, o docente deve dedicar certa atenção à experiência pessoal trazida pelo seu estudante, pois essas memórias anteriores poderão desencadear uma sequência de aprendizados, capazes de proporcionar seu desenvolvimento. Consoante com Vygotsky (1991, p. $61)$

[...] nossa análise modifica a visão tradicional, segundo a qual, no momento em que uma criança assimila o significado de uma palavra, ou domina uma operação tal como a adição ou a linguagem escrita, seus processos de desenvolvimento estão basicamente completos. Na verdade, naquele momento eles apenas começaram. A maior consequência de se analisar o processo educacional desta maneira, é mostrar que, por exemplo, o domínio inicial das quatro operações aritméticas fornece a base para o desenvolvimento subsequente de vários processos internos altamente complexos no pensamento das crianças.

Embora permaneça a ideia de uma relação direta entre aprendizado e desenvolvimento, há de se destacar que não existe um paralelismo, ou seja, um não acompanha o outro necessariamente, tampouco na mesma velocidade; não é como uma sombra que segue sua fonte (VYGOTSKY, 1991). “[...] O aprendizado desperta vários processos internos de desenvolvimento, que são capazes de operar somente quando a criança interage com pessoas em seu ambiente e quando em operação com seus companheiros" (VYGOTSKY, 1991, p. 60). Esse movimento de internalização é introspectivo, é para dentro de si mesmo, no sentido de que

\footnotetext{
${ }^{4}$ Embora exista uma variedade de pesquisas e proposições em educação matemática sobre as frações, por exemplo, Giménez e Bairral (2004), essa é uma dificuldade ainda recorrente no pensamento numérico dos estudantes.

${ }^{5}$ THORNDIKE, E. L. Principles of teaching based on Psychology. New York: A. G. Seiler, 1906.
} 
[...] um processo interpessoal é transformado num processo intrapessoal. Todas as funções no desenvolvimento da criança aparecem duas vezes: primeiro, no nível social, e, depois, no nível individual; primeiro, entre pessoas (interpsicológica), e, depois, no interior da criança (intrapsicológica). Isso se aplica igualmente para a atenção voluntária, para a memória lógica e para a formação de conceitos. (VYGOTSKY, 1991, p. 41)

Marques e Bairral (2014) destacam que nenhum docente é capaz de realizar o processo de internalização pelos seus alunos, mas, “[...] uma vez internalizados, esses processos tornam-se parte das aquisições do desenvolvimento independente da criança” (VYGOTSKY, 1991, p. 60). No entanto, é possível que, através do fornecimento de pistas pelo professor, torne factível ao aluno desenvolver atividades que não realizaria sozinho, mas que talvez estivesse próximo de fazê-lo.

Quando um estudante consegue solucionar um problema mediante o fornecimento de pistas fornecidas por alguém mais experiente ou com a colaboração de outros alunos, dizemos que o discente transitou pela zona de desenvolvimento proximal (VYGOSTKY, 1991), ou seja, partiu de um nível de conhecimento real, de algo que já dominava e era capaz de realizar sozinho, e atingiu um nível de conhecimento potencial, no qual, através de certo auxílio, realizou uma tarefa que por pouco ainda não era capaz de realizar. Vygotsky (1991, p. 58) sinaliza que

“[...] assim, a zona de desenvolvimento proximal permite-nos delinear o futuro imediato da criança e seu estado dinâmico de desenvolvimento, propiciando o acesso não somente ao que já foi atingido através do desenvolvimento, como também àquilo que está em processo de maturação".

No entanto, Vygotsky (1991) sublinha que, por muito tempo, estudiosos mais perspicazes nunca consideraram que esse estágio no qual a criança estaria na iminência de realizar uma atividade poderia ser bem mais indicativo do seu desenvolvimento mental do que o estágio em que consegue realizar as tarefas sozinha. Para que o estudante transite pela zona de desenvolvimento proximal faz-se necessária a intervenção, a ajuda de uma pessoa mais experiente ou mesmo a colaboração de seus pares. Quando acontece através do fornecimento de pistas pelo professor por exemplo, mediante a proposição de uma sequência didática, convém salientarmos que o docente não deve ter as indicações prontas, mas apresentadas de acordo com a interação que se segue com seu discente.

Desta forma, a (re)negociação proporcionada pelas interações entre aluno e professor converge para a questão da arquitetônica dialógica bakhtiniana, indicando que o ser humano deve ser compreendido de maneira ativa, ou seja, no concílio dialógico entre dois atores que trocam enunciados, perseguem alternativas, contrapõem, ponderam, dentro de um contexto social (FREITAS, 2009). Consoante ao exposto, Freitas (2007, p. 29) sinaliza que

[...] Bakhtin assume a interação como essencial no estudo dos fenômenos humanos. Salienta o valor da compreensão construída a partir dos textos signos 
criados pelo homem, portanto, assinalando o caráter interpretativo dos sentidos construídos. O sujeito é percebido em sua singularidade, mas situado em sua relação com o contexto histórico-social, portanto, na pesquisa, o que acontece não é um encontro de psiqués individuais, mas uma relação de textos com o contexto.

Trazendo ao diálogo a questão do acabamento, segundo Bakhtin (1997), na relação entre o autor e o herói, podemos projetar sobre as interações entre o eu e o outro, que na sua dialogia vão (re)negociando, (re)argumentando, admitindo a recíproca existência, possibilitando o acabamento de cada um deles, “[...] pois o acabamento só pode vir do exterior” (BAKHTIN, 1997, p. 15). Embora o estudioso assegure que nossa consciência é quem dará a última palavra, não é ela, a nossa consciência, que endossará nosso acabamento, mas sim o acabamento que adquirimos no outro é que certificará o nosso próprio. Desta forma, entendemos que, quando se trava um diálogo entre professor e aluno, cada um vai produzindo um acabamento no outro durante as interações, podendo convergir para reflexões que contribuam ou não para um processo de aprendizagem.

\section{Então, como algumas pessoas costumam pensar, dividir diminui?}

A fim de investigarmos aspectos do raciocínio matemático em tarefas realizadas com a calculadora e possíveis contribuições para a aprendizagem, foi oferecido a alunos ${ }^{6}$ de um curso técnico do primeiro ano do Ensino Médio Profissionalizante de uma escola pública na cidade do Rio de Janeiro um curso intitulado Calculadoras no Ensino Médio $^{7}$, no qual implementamos atividades instigadoras (MARQUES; BAIRRAL, 2014) mediante a utilização da calculadora comum de bolso para a realização das mesmas, as quais foram realizadas em duplas ou em trios. Uma das características dessas atividades consiste em despertar reflexão sobre a relativização de verdades matemáticas, a qual nos parece ser percebida na situação de aprendizagem a ser analisada, uma vez que existe indícios de que os alunos acreditam que dividir sempre diminui.

A atividade denominada Diversificando (Figura 1) continha algumas expressões a serem solucionadas, abarcando o domínio e a compreensão de operações matemáticas, na qual os estudantes decidiriam por operações alternativas ou diferentes modos de resolução, além de verificar possíveis erros cometidos para encontrar as respostas.

\footnotetext{
${ }^{6}$ Discentes com idade aproximada entre 14 e 16 anos.

${ }^{7}$ Curso ministrado pelo autor para um grupo de alunos oriundos de quatro turmas distintas, voluntários a participar. Naquela oportunidade o pesquisador realizava investigação na qual se encontrava inserido no contexto, pois o mesmo era professor daqueles estudantes, o que lhe permitira realizar observações em tempo real.
} 
Figura 1 - Atividade 7: Diversificando.

\section{Atividade 7: Diversificando}

Escreva uma sequência de teclas para resolver as expressões abaixo, utilizando-se a tecla = apenas uma vez ‘ sem usar as teclas de memória. Reflita sobre possíveis enganos passiveis de serem cometidos.

a) $2500=$

0,5

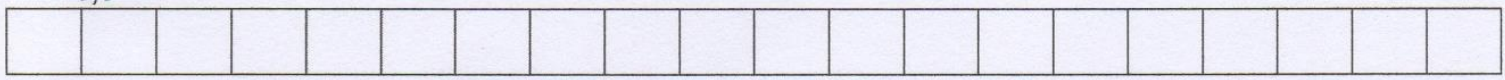

b) $\quad \underline{538}=$

$3 \times 15$

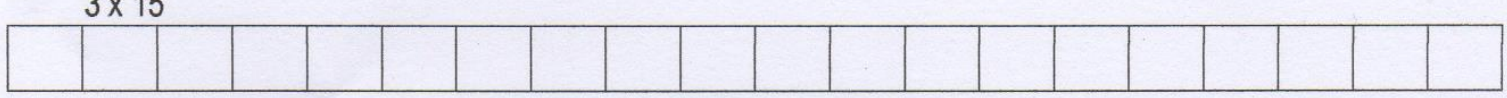

c) $\underline{2.1 \times 10^{6}}=$

\section{$\frac{2,1 \times 106}{144}$}

\begin{tabular}{|l|l|l|l|l|l|l|l|l|l|l|l|l|l|l|l|l|l|l|l|}
\hline & & & & & & & & & & & & & & & & & & & \\
\hline
\end{tabular}

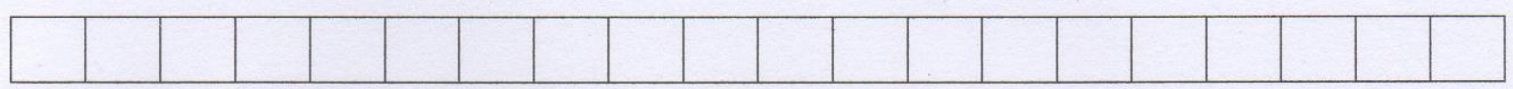

d) $\underline{3,14 \times 9,5 \times 10^{5} \times 124}=$
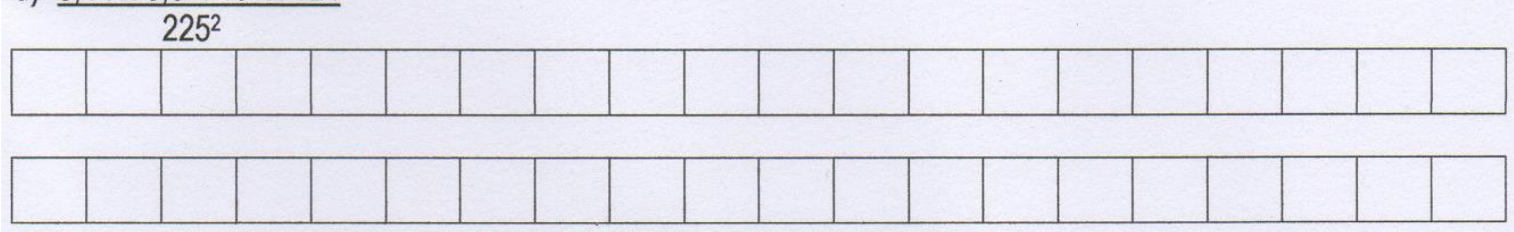

Fonte: Apostila do curso Calculadoras no Ensino Médio.

O cruzamento de informações dos mais variados meios de coleta de dados, técnica conhecida como triangulação (ALVES-MAZZOTTI; GEWANDSZNAJDER, 1998), pode nos permitir um entendimento mais apurado. Nossa análise vai se concentrar apenas no item "a" da atividade em questão, observando-se, primeiramente, a resolução apresentada por Silas e Lucas Motta $^{8}$ (Figura 2), para solucionar a divisão $2500 \div 0,5$. Para isso, nos pautaremos em informações provenientes (i) do diário de campo do investigador, redigido pelo pesquisador logo após cada encontro, (ii) da resposta dos alunos para a atividade proposta, com resoluções e observações efetuadas na própria folha das atividades, (iii) das reflexões individuais dos estudantes, preenchidas em formulário fornecido após cada implementação, e (iv) da gravação em áudio de diálogos entre professor (o próprio pesquisador) e seus estudantes, durante algumas atividades.

\footnotetext{
${ }^{8}$ A opção pela utilização dos nomes reais dos participantes se deve ao fato de termos obtido autorização dos seus responsáveis. Desta forma, pudemos manter as imagens sem edição para facilitar a compreensão do leitor.
} 
Figura 2 - Resolução apresentada por Silas e Lucas Motta.

\section{Atividade 7: Diversificando}

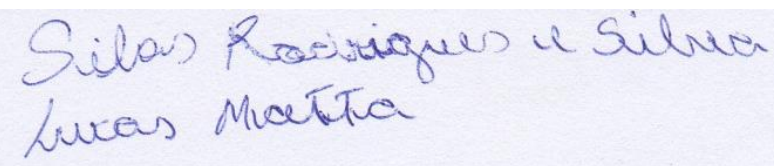

Escreva uma sequência de teclas para resolver as expressões abaixo, utilizando-se a tecla = apenas uma vez e sem usar as teclas de memória. Reflita sobre possiveis enganos passiveis de serem cometidos.

a) $2500=$

\begin{tabular}{|l|l|l|l|l|l|l|l|l|l|l|l|l|l|l|l|l|l|l|l|}
\hline 0,5 & 6 & 0 & 0 & $\div$ & 1 & $\times$ & 0 & 0 & 3 & $=$ & 1 & 2 & 5 & 0 & & & & & \\
\hline
\end{tabular}

Fonte: Fragmento de instrumento de pesquisa.

Essa resposta chamou a atenção, pois percebemos que alguns alunos traziam consigo a ideia de que, ao efetuar a divisão em questão, o resultado seria a metade do número que se encontrava no denominador $(2500 \div 2=1250)$, o que passamos a entender que para eles seria uma verdade matemática, ou seja, que dividir diminui. "Guilherme Fidélis disse que logo vinha à mente que deveria dar a metade, mas que não era isso que acontecia” (DIÁRIO DO PESQUISADOR, 24/08/2012). Anna Carolina e Lucas Santos, embora tivessem escrito a resolução de forma correta, endossaram a afirmação equivocada de Guilherme, conforme mostrado na Figura 3.

Figura 3 - Justificativa apresentada na resposta de Anna Carolina e Lucas Santos.

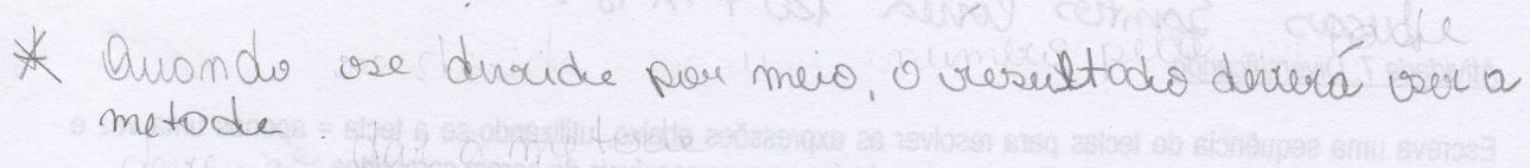

Fonte: Fragmento de instrumento de pesquisa.

A justificativa exibida por Silas e Lucas Motta para que o resultado não fosse a metade (Figura 4) foi bastante curiosa, uma vez que utilizaram a fração $1 / 2$, equivalente ao decimal 0,5 , mas não estavam conseguindo fazer a relação de forma adequada, a fim de encontrar o resultado correto para aquela divisão, pois os mesmos introduziam na calculadora exatamente como escrito na folha de respostas, acarretando uma sequência de operações diferente da proposta na tarefa. Isaque percebera que se transformasse o número decimal 0,5 em fração e utilizasse as operações com essa nova forma, tal resposta, a metade, seria compatível. Ao afirmar que "o resultado era possível porque na divisão se multiplicava pelo inverso, estabelecendo a relação entre 0,5 e 1/2, o discente ratifica a validade de sua ideia” (DIÁRIO DO PESQUISADOR, 24/08/2012). 
Figura 4 - Justificativa apresentada na resposta de Silas e Lucas Motta.

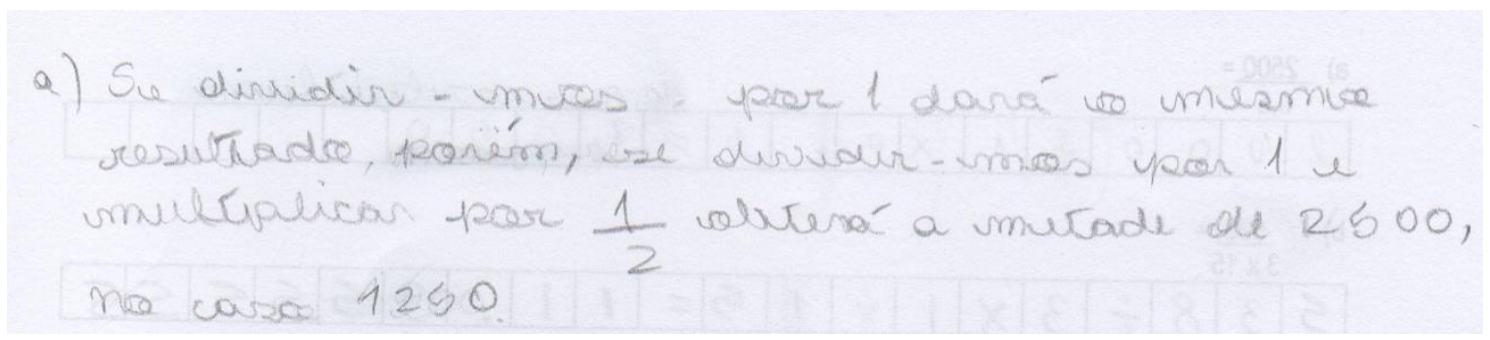

Fonte: Fragmento de instrumento de pesquisa.

Diante da solução e justificativa expressas por Silas e Lucas Motta, o pesquisador pensou numa estratégia que fosse capaz de fazê-los refletir sobre o que escreveram e pudessem, através das pistas que eram fornecidas, desmistificar aquela questão de que a resposta da tarefa seria a metade, conforme registrado no diário do pesquisador (24/08/2012).

Silas e Lucas Motta, que também achavam que deveria dar a metade, escreveram a expressão 2500 / 1 x 0,5 e encontraram 1250, a metade. Pedi a eles que digitassem na calculadora a expressão como tinha sido solicitada, 2500 / 0,5 e encontraram 5000. Ficaram confusos. Pedi-lhes, então, que fizessem $2500 / 0,4,2500 / 0,2$, $2500 / 0,05$, e foram verificando resultados cada vez maiores. À medida que conversávamos, foram percebendo que essa divisão era meio diferente. Com números entre 0 e 1 no divisor, o resultado era sempre maior. Aproveitei e lhes pedi para realizar a multiplicação 2500 x 0,8 e 2500 x 0,6. Encontraram números menores. Chegaram à conclusão de que na divisão aumentava e na multiplicação diminuía.

A certeza que aqueles alunos tinham quanto à sua resposta, transformou-se em hesitação e, aos poucos, instigados por aquelas novas respostas obtidas através de cálculos semelhantes, os estudantes foram estabelecendo uma nova realidade. Os estudantes tinham um nível real de conhecimento a ser explorado que, mediante sinalizações realizadas pelo professor, poderia atingir um novo nível, um nível em estado de potência, ou seja, uma transição pela zona de desenvolvimento proximal (VYGOTSKY, 1991). Tais indicações eram (re)elaboradas pelo docente à medida que interagia com seus alunos em um concílio dialógico, (re)argumentando como sujeitos que permutam enunciados, permitindo, assim, um acabamento recíproco (BAKHTIN, 1997). Desta forma, aproveitamos a oportunidade para realizar a operação inversa (multiplicação), utilizando-se números decimais que se localizam entre 0 e 1 . Como podemos observar na Figura 5, Silas e Lucas Motta apresentaram indícios de que uma nova realidade conceitual acabava de se estabelecer para eles e que, agora, a resposta metade já poderia fazer sentido como solução daquela atividade. 
Figura 5 - Justificativa apresentada na resposta de Silas e Lucas Motta.

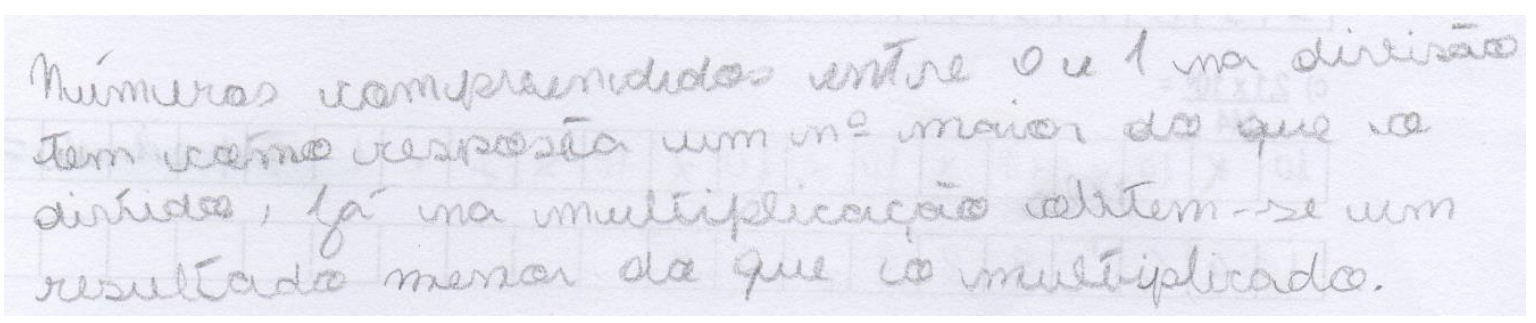

Fonte: Fragmento de instrumento de pesquisa.

Reunindo as informações até o momento apresentadas sobre as interações dos alunos Silas e Lucas Motta, Anna Carolina e Lucas Santos, além da observação do estudante Isaque, podemos apresentar um esquema (Figura 6), através do qual é possível perceber a construção do conhecimento por Silas e Lucas Motta, a partir das pistas fornecidas pelo professor, bem como as inserções realizadas por seus colegas, o que lhes permitiu atingir um novo estágio de conhecimento, a partir de conhecimentos prévios em direção a conhecimentos em estado de potência (VYGOTSKY, 1991).

Figura 6 - Evolução de Silas e Lucas Motta.

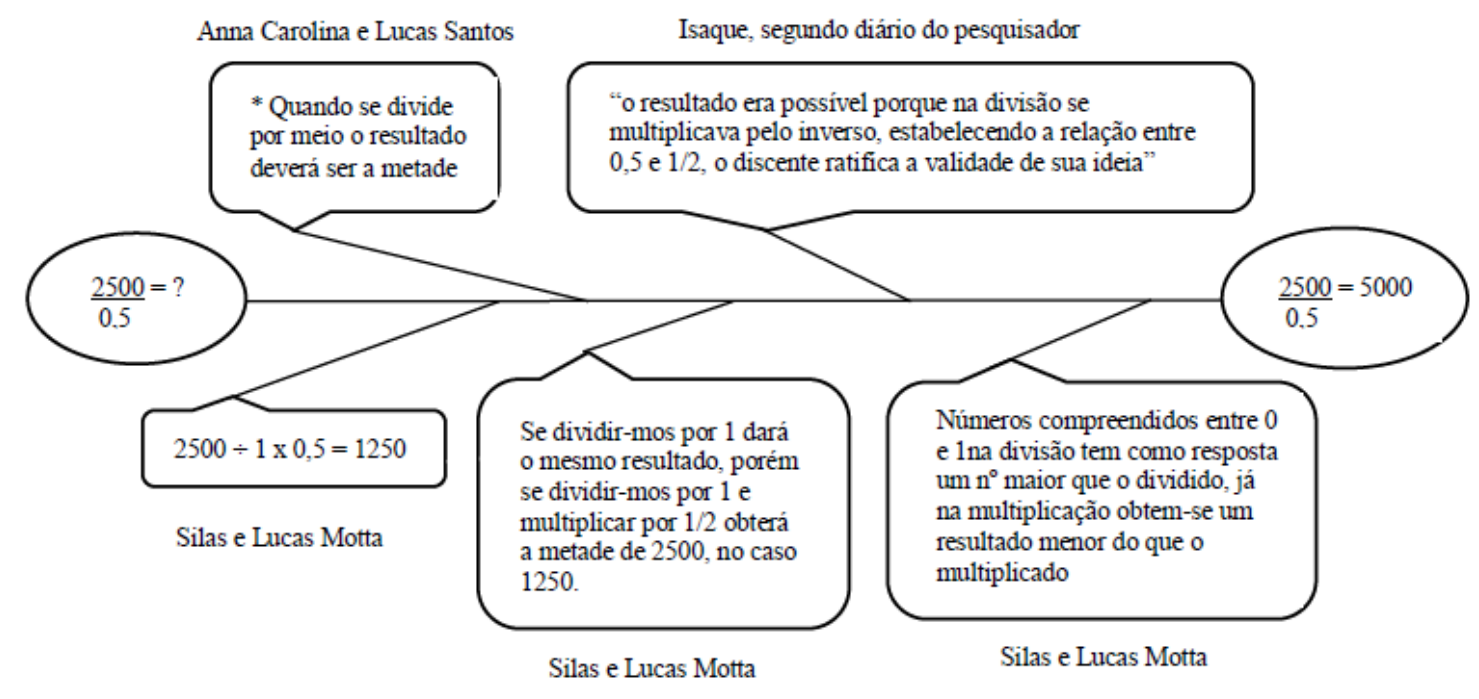

Fonte: Elaborada pelo autor.

Embora, aparentemente, a atividade fosse fácil, relatado por grande parte dos alunos, nossos registros mostraram que algumas perguntas foram suficientes para desestabilizá-los e fazêlos refletir sobre suas respostas, consoante com o assinalado no diário do pesquisador (24/08/2012):

A primeira tarefa propunha a divisão por um número decimal compreendido entre 0 e 1. Eles acharam muito fácil a execução na calculadora, porém resolvi questionar o resultado: "Essa resposta está certa mesmo? Como posso dividir e encontrar um número maior?" Percebi que criei muitas dúvidas. Como no segundo 
encontro descobrimos que a calculadora comum realiza os cálculos na ordem digitada, alguns alunos passaram a desconfiar do resultado.

$\mathrm{O}$ excerto anterior revelava a possibilidade de que aquelas pistas pudessem auxiliar na transição dos alunos pela zona de desenvolvimento proximal (VYGOTSKY, 1991), objetivando alcançar um novo nível de conhecimento. No entanto, a fim de elucidar esse momento, vamos reparar o que ocorreu com a aluna Gleyciane que, naquela oportunidade, realizou as atividades em parceria com João. Esta dupla encontrava-se no grupo dos alunos que achou a tarefa fácil, apresentando a resposta certa de imediato (Figura 7).

Figura 7 - Resolução apresentada por Gleyciane e João.

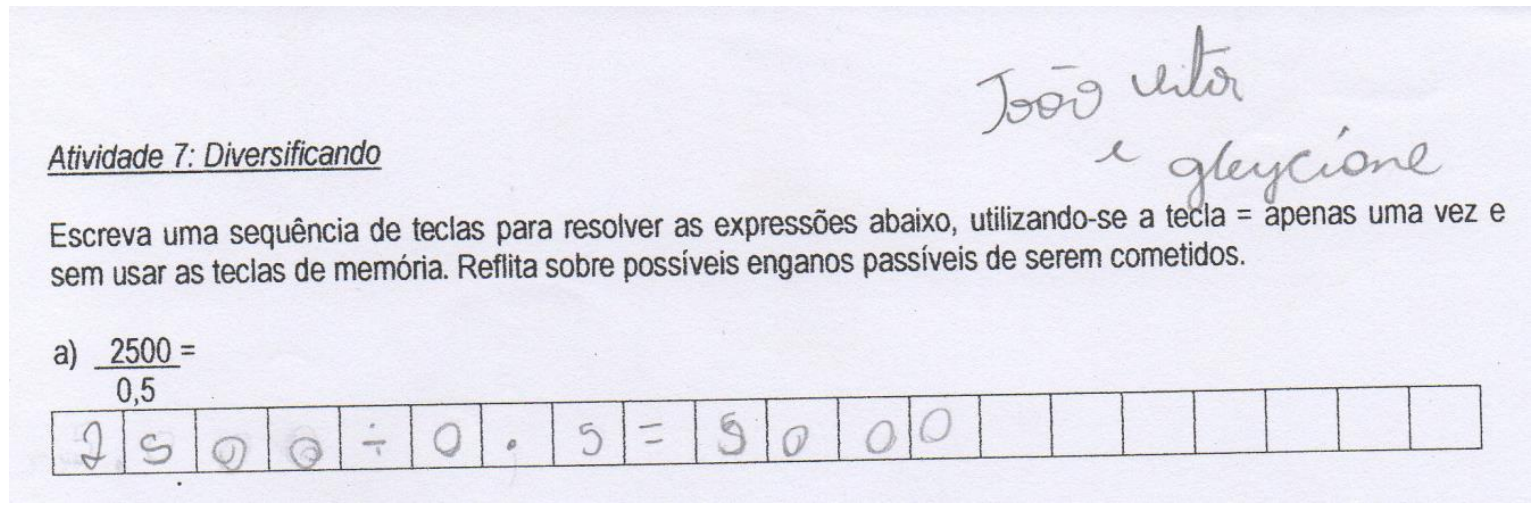

Fonte: Fragmento de instrumento de pesquisa.

Ao lançarmos as indagações "Essa resposta está certa mesmo? Como posso dividir e encontrar um número maior?" (DIÁRIO DO PESQUISADOR, 24/08/2012), notamos que parte dos estudantes acabou duvidando de suas próprias respostas, ainda que resolvidas com o auxílio da calculadora, fazendo com que se sentissem inseguros e tivessem que refletir acerca da questão. O excerto a seguir, extraído de uma gravação de áudio de um diálogo entre o professor e a dupla formada por Gleyciane e João, demonstra ter havido desestabilização dessa aluna.

Professor: Você está pegando um número, dividindo por outro e a resposta está sendo um número maior do que o inicial. Pode isso?

Gleyciane: Não.

Professor: Você acha que não pode por quê?

Gleyciane: Não, acho que pode, professor, porque a calculadora tá fazendo, mas..

Professor: Mas o quê?

Professor: Que tipo de número é esse que está no denominador?

João: Número decimal.

Professor: Mas ele está compreendido entre zero e qual número?

Gleyciane: 0 e 1.

Professor: 0 e 1

Professor: O que acontece se eu dividir por outro número diferente desse, por exemplo, 0,8 ?

Gleyciane: Ele arredonda. 
Inicialmente, é possível fazer alusão às atividades instigadoras que apresentam como uma de suas características despertar a reflexão sobre a relativização de verdades matemáticas (MARQUES; BAIRRAL, 2014). Qual verdade matemática os estudantes entendem estar em jogo nessa atividade? Será que quando efetuamos uma divisão sempre teremos como resultado um número menor que o inicial? Este seria um conhecimento prévio que os alunos carregavam consigo (VYGOTSKY, 1991)? Isto é uma verdade matemática ou não? Gleyciane acreditava numa verdade que se transformou em dúvida, que acabou ficando relativa?

Dois aspectos pretendemos aqui destacar. $\mathrm{O}$ primeiro é que, embora a atividade tenha sido planejada com caráter instigador, diferentemente do primeiro exemplo (Silas e Lucas Motta), parece não ter se apresentado inicialmente como tal, pois os alunos mostraram uma resolução correta sem qualquer tipo de questionamento. No entanto, entendemos que a atividade "se transformou" em instigadora a partir do momento que o professor inseriu, através de sucessivas mediações (VYGOTSKY, 1991), algumas indagações acerca dos resultados apresentados, instigando os discentes a refletirem sobre o que haviam escrito como resposta, após terem utilizado a calculadora. Também, à medida que as perguntas eram realizadas pelo docente, as respostas dadas pelos alunos faziam com que o mesmo se reorganizasse para uma nova indagação, da mesma forma que o outro bakhtiniano vai dando acabamento ao eu enunciante, admitindo a sua existência e interagindo com ele, tornando possível o diálogo e situando-o no contexto (FREITAS, 2007), os estudantes o faziam com seu mestre. Essa prática dialógica mostra-se importante no aprendizado de ambos, professores e alunos (BAKHTIN, 1997). Ao docente, a necessidade de refletir em tempo real (re)elaborando mentalmente possíveis questões (ou outras situações de aprendizagem) e, ao discente, o exercício argumentativo de continuar aprimorando suas formas de convencimento.

O segundo aspecto revela que Gleyciane (tinha como certa a resolução apresentada pela sua dupla) começou a se sentir instigada a partir das perguntas do professor, concordando que não seria possível numa divisão se obter um número maior que o inicial, mas logo admitindo que isso poderia ser viável, mas sem saber explicar por que motivo, apenas creditando a resposta ao fato de ter sido a conta realizada pela calculadora. Embora tivesse reconhecido que o número apresentado no denominador $(0,5)$ era um número decimal compreendido entre 0 e 1 , as pistas fornecidas pelo professor parecem não tê-la auxiliado completamente, naquele momento, pois, ao ser questionada sobre o que aconteceria se dividisse por 0,8 no lugar de 0,5 , Gleyciane respondeu que a calculadora arredondaria. Face ao exposto, parece-nos que a aluna aparentou não ter conseguido atingir, naquele momento, um novo nível de conhecimento, conforme explicitado no seu momento de reflexão (Figura 8), ou seja, não foi possível passar de um nível de conhecimento a outro, através da zona de desenvolvimento proximal (VYGOTSKY, 1991). 
Figura 8 - Momento de reflexão de Gleyciane.

\section{CALCULADORAS NO ENSINO MÉDIO}

$$
\text { Encontro do dia } 24 / 08 / 12
$$

Aluno(a): Eleufarane masemento $R$. banto

Momento de Reflexão: escreva o que aprendeu, o que gostou (ou não), o que ainda está em dúvida, o que foi significativo, ou qualquer outro aspecto que ache interessante a respeito do encontro de

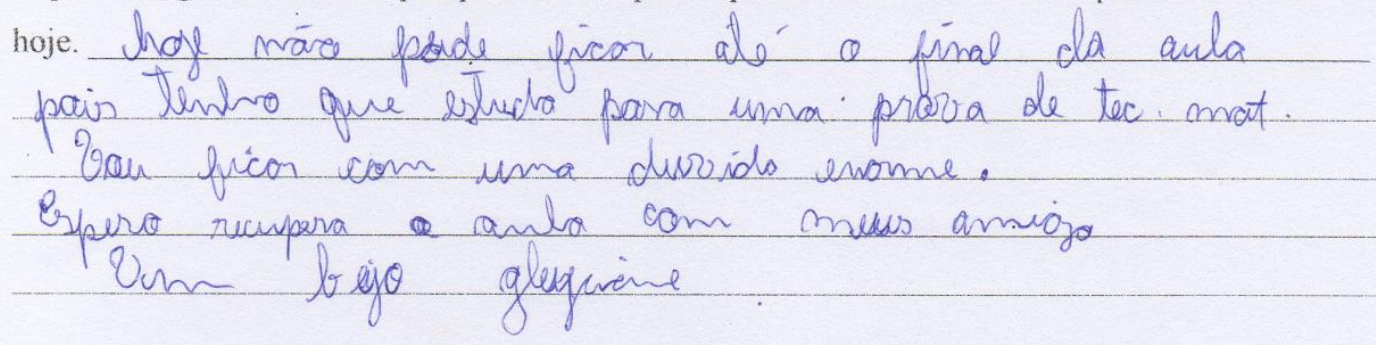

Fonte: Fragmento de instrumento de pesquisa.

\section{Divisão feita!}

Embora a calculadora ainda seja um recurso meio "velho", percebemos ainda grande ausência desse instrumento nas salas de aula. Ao introduzirmos a categoria de atividades instigadoras associadas à calculadora (MARQUES; BAIRRAL, 2014), pretendemos resgatar o seu uso e mostrar que a mesma pode, mesmo em tempos atuais, ser uma "novidade" em sala de aula. Optamos por suscitar nesse artigo uma reflexão articulando dois âmbitos "antigos" (recurso: calculadora, conteúdo: divisão por meio) e a possibilidade de um espaço de aprendizagem "atual" mediante uma prática dialógica que instigue descobertas pelos aprendizes.

Silas e Lucas Motta, mesmo com o auxílio da calculadora, realizaram a divisão 2500/0,5 e encontraram 1250. Para eles, a atividade se mostrou instigadora desde o início, uma vez que aquele 0,5 no denominador remetia à noção de metade. Como sinaliza Vygotsky (1991, p. 56), “[...] crianças têm sua própria aritmética pré-escolar", ou seja, para aqueles estudantes a aritmética que traziam consigo lhes possibilitou afirmar que o resultado seria a metade do número indicado no numerador da fração. Neste caso, foi preciso o fornecimento de pistas (VYGOTSKY, 1991) para que os mesmos, através da mediação e interação, pudessem chegar a uma nova verdade, a um novo nível de conhecimento.

Para Gleyciane, a atividade somente passou a ter o caráter instigador a partir do momento em que o docente introduziu questões que pudessem desestabilizar a sua posição em relação à resposta dada. Assim como Silas e Lucas Motta, começou a achar esquisito obter um número maior na divisão. Com o auxílio da calculadora, havia resolvido rapidamente a questão, mas, após as indagações, colocou em dúvida a resposta fornecida pelo recurso. O diálogo apresentado mostra que os atores, aluna e professor, parecem não ter conseguido dar acabamento um ao outro (BAKHTIN, 
1997), e que o docente fracassa na tentativa de fazer com que ela saia de um nível interpessoal em direção a uma compreensão num nível individual, intrapessoal (VYGOTSKY, 1991).

Muito ainda há de ser feito, seja com calculadoras, computadores, celulares, tablets ou qualquer outro tipo de tecnologia que possa ser introduzida em sala de aula, associada ou não a atividades instigadoras. Em ambos os casos, há indícios que a atividade desenvolvida despertou reflexão sobre a relativização de verdades matemáticas, uma das principais características desse tipo de tarefa. Mas qual seria essa verdade para eles? Dividir sempre diminui?

\section{Referências}

ALBIN, I. C. C. Dicionário Cravo Albin da Música Popular Brasileira. Disponível em: <http://www.dicionariompb.com.br/ataulfo-alves/dados-artisticos>. Acesso em: 16 Fev 2015.

ALVES-MAZZOTTI, A.J.; GEWANDSZNAJER, F. O método nas ciências naturais e sociais: pesquisa quantitativa e qualitativa. São Paulo: Pioneira, 1998.

BAKHTIN, M. Estética da Criação Verbal. São Paulo: Martins Fontes, 1997.

BAKHTIN, M. Marxismo e Filosofia da linguagem. 12a ed. São Paulo: Hucitec, 2006.

BIGODE, A. J. L. Explorando o uso da calculadora no ensino de Matemática para jovens e adultos. In: VÓVIO, Cláudia; IRELAND, Timothy (orgs.). Construção coletiva: contribuições à educação de jovens e adultos. Coleção Educação para Todos. Brasília: MEC, 2005.

BIGODE, A. J. L. Explorando o uso da calculadora no ensino de Matemática para jovens e adultos. Alfabetização e cidadania, n. 6, 1997, p. 67-79.

BORBA, M.C.; ARAÚJO, J.L. Construindo pesquisas coletivamente em Educação Matemática. In: BORBA, M.C.; ARAÚJO, J.L. (org) Pesquisa qualitativa em educação matemática. Belo Horizonte: Autêntica Editora, 2012.

BORBA, R. E. S. R.; SELVA, A. C. V. O que pesquisas têm evidenciado sobre o uso da calculadora na sala de aula dos anos iniciais de escolarização? In: Educação Matemática em Revista, v.1, n.10, 2009, p. 49-63.

FLICK, U. Desenho da pesquisa qualitativa. Porto Alegre: Artmed, 2009.

FREITAS, M.T.A. A pesquisa de abordagem histórico-cultural: um espaço educativo de constituição de sujeitos. In: Revista Teias, v.10, n. 19, 2009.

FREITAS, M.T.A. A perspectiva sócio-histórica: uma visão humana da construção do conhecimento. In: FREITAS, M.T.; SOUZA, S.J.; KRAMER, S. (orgs.). Ciências humanas e pesquisa: leituras de Mikhail Bakhtin. São Paulo: Cortez, 2007.

GIMÉNEZ, J.; BAIRRAL, M. A. Frações no Ensino Fundamental: Conceituação, Jogos e Atividades Lúdicas. Seropédica: Edur, 2004.

LUDKE, M.; ANDRÉ, M.E.D.A. Pesquisa em educação: abordagens qualitativas. São Paulo: EPU, 1986.

MARQUES, W., BAIRRAL, M. Na calculadora é ponto ou vírgula? Analisando interações discentes sob as lentes de Vygotsky e Bakhtin. Seropédica: EDUR, 2014.

MARQUES, W. S. De que forma a calculadora auxilia no pensamento matemático? In: Anais do XI SEAMA - Semana Acadêmica de Matemática da UFRRJ. Seropédica, RJ, 2013. 
MARQUES, W. S. Calculadoras em aulas de matemática: perspectiva instigadora e interativa. In: Anais do VI EMEM - Encontro Mineiro de Educação Matemática. Juiz de Fora, MG, 2012.

SCHEFFER, N. F. A argumentação matemática na exploração de atividades com a calculadora gráfica e softwares gratuitos. In: BAIRRAL, M.A. (org.). Pesquisa, ensino e inovação com tecnologias em educação matemática: de calculadoras a ambientes virtuais. Seropédica: Edur, 2012.

SEIXAS, S. R., SILVA, D. As competências que a calculadora gráfica promove no ensino/aprendizagem da matemática: um estudo de caso numa turma do $11^{\circ}$ ano. In: Revista Interacções, v. 6, n. 15, 2010, p. 141-172.

SELVA, A. C. V., BORBA, R. E. S. R. O uso da calculadora nos anos iniciais do ensino fundamental. Coleção Tendências em Educação Matemática., 2010.

SILVA, A. L. V., CASTRO, M. R. Números reais no ensino médio e o uso da calculadora: identificando e analisando imagens conceituais. In: BAIRRAL, M.A. (org.). Pesquisa, ensino e inovação com tecnologias em educação matemática: de calculadoras a ambientes virtuais. Seropédica: EDUR, 2012.

VYGOTSKY, L. S. A formação social da mente. São Paulo: Martins Fontes, 1991.

Submetido em março de 2016 Aprovado em junho de 2016 